\title{
The Prevalence of Intradialytic Hypotension in Patients on Conventional Hemodialysis: A Systematic Review with Meta-Analysis
}

\author{
Johanna Kuipers $^{a}$ Loes M. Verboom ${ }^{b}$ Karin J.R. Ipema ${ }^{b}$ Wolter Paans ${ }^{c}$ \\ Wim P. Krijnenc Carlo A.J.M. Gaillard ${ }^{d}$ Ralf Westerhuis ${ }^{a}$ Casper F.M. Franssen ${ }^{b}$ \\ ${ }^{a}$ Dialysis Center Groningen, Groningen, The Netherlands; ${ }^{b}$ Department of Internal Medicine, Division of \\ Nephrology, University Medical Center Groningen, University of Groningen, Groningen, The Netherlands; ${ }^{\mathrm{C}} \mathrm{Hanze}$ \\ University Groningen, University of Applied Sciences, Groningen, The Netherlands; ${ }^{\mathrm{d}}$ Division of Internal Medicine \\ and Dermatology, University of Utrecht, University Medical Center Utrecht, Utrecht, The Netherlands
}

\section{Keywords}

Dialysis · Intradialytic hypotension · Prevalence

\begin{abstract}
Background: Intradialytic hypotension (IDH) is considered to be a frequent complication of hemodialysis (HD) and is associated with symptom burden, increased incidence of access failure, cardiovascular events, and higher mortality. This systematic literature review aims to analyse studies that investigated the prevalence of IDH. A complicating factor herein is that many different definitions of IDH are used in literature. Methods: A systematic literature search from databases, Medline, Cinahl, EMBASE, and the Cochrane library to identify studies reporting on the actual prevalence of IDH was conducted. Studies were categorized by the type of definition used for the prevalence of IDH. A meta-analysis of the prevalence of IDH was performed. Results: In a meta-analysis comprising 4 studies including 1,694 patients and 4 studies including 13,189 patients, the prevalence of HD sessions complicated by IDH was 10.1 and $11.6 \%$ for the European Best Practice Guideline (EBPG) definition and the Nadir $<90$ definition, respectively. The proportion of patients with fre-
\end{abstract}

quent IDH could not reliably be established because of the wide range in cutoff values that were used to identify patients with frequent IDH. There was a large variety in the prevalence of symptoms and interventions. Major risk factors associated with IDH across studies were diabetes, a higher interdialytic weight gain, female gender, and lower body weight. Conclusion: Our meta-analysis suggests that the prevalence of IDH is lower than $12 \%$ for both the EBPG and the Nadir $<90$ definition which is much lower than stated in most reviews.

(C) 2019 The Author(s)

Published by S. Karger AG, Basel

\section{Introduction}

Intradialytic hypotension (IDH) is considered to be one of the most frequent complications of hemodialysis (HD). IDH is associated with a considerable symptom burden and an increased incidence of access failure, cardiovascular events, and mortality [1-6]. The pathophysiology of IDH and methods to prevent this complication have been extensively investigated $[1,5]$. Over the years,

\begin{tabular}{ll}
\hline KARGER & $\begin{array}{l}\text { (c) } 2019 \text { The Author(s) } \\
\text { Published by S. Karger AG, Basel }\end{array}$ \\
E-Mail karger@karger.com & $\begin{array}{l}\text { This article is licensed under the Creative Commons Attribution- } \\
\text { NonCommercial-NoDerivatives 4.0 International License (CC BY- } \\
\text { NC-ND) (http://www.karger.com/Services/OpenAccessLicense). } \\
\text { Usww.karger.com/ajn } \\
\text { tribution of modified material requires written permission. }\end{array}$
\end{tabular}

Johanna Kuipers

Dialyse Centrum Groningen

Hanzeplein 1

NL-9713 GZ Groningen (The Netherlands)

E-Mail h.kuipers@dcg.nl 
dialysis techniques have improved, and there is more attention for the prevention of dialysis hypotension, for example, by lowering the dialysate temperature [7] and monitoring of relative blood volume changes [8]. At the same time, the average age of dialysis patients as well as the proportion of patients with significant comorbidities such as diabetes mellitus and heart failure has increased $[9,10]$. Therefore, the exact prevalence of dialysis hypotension is unknown. The major aim of this systematic literature review is to present an overview of studies that investigated the prevalence of IDH. A complicating factor in the analysis of the prevalence of IDH is that many different definitions are used. In this review, we categorized studies by the type of definition used. The second goal was to assess the frequency of patient symptoms and nursing interventions related to IDH. Finally, we aimed to assess patient and treatment factors associated with IDH.

\section{Materials and Methods}

\section{Study Protocol and Information Sources}

This systematic review was performed according to the preferred reporting items for systematic reviews, a meta-analyses checklist [11]. The literature search included articles that were published between January 1, 1980, and January 1, 2019, from databases of Medline, Cinahl, EMBASE, and The Cochrane Library.

\section{Eligibility Criteria}

Studies were eligible for inclusion if the following criteria were met: (1) HD-treated adults (aged $\geq 18$ years) with chronic kidney disease; (2) outcome of interest was the actually studied prevalence of IDH in HD patients; and (3) full-length articles without language restriction, published between January 1, 1980, and January 1,2019 . Data were required to be obtained by original research and not from reviews. The selection procedure included cohort studies, observational studies, and controlled clinical trials. Articles were excluded (based upon methodology) when the focus was on the comparison between patients with and those without hypotension since this design precluded the unbiased assessment of the prevalence of IDH.

\section{Search Strategy}

Different combinations of terms and search strings were used in order to identify eligible articles. The search strategy for Medline is detailed in online supplementary File 1 (for all online suppl. material, see www.karger.com/doi/10.1159/000500877). The same strategy was followed in all electronic databases searched.

\section{Study Selection and Data Collection}

Two reviewers (L.M.V., J.K.) separately screened the titles and abstracts of studies that were identified through electronic searching to select studies that were potentially eligible for inclusion. Additional studies were identified through checking relevant refer- ences of the included studies. After screening, the reviewers discussed any difference in study selection. Studies were found eligible for inclusion if outcomes were available for IDH prevalence.

\section{Risk of Bias and Quality Assessment}

All full-text versions of potentially relevant studies were independently screened by 2 reviewers (L.M.V., J.K.) to identify whether studies were eligible for inclusion. Study quality was assessed using the Newcastle-Ottawa Scale for cohort studies [12]. The scale consists of 3 quality criteria: selection, comparability, and outcome. The maximal score is 9 points ( 4 for selection, 2 for comparability, and 3 for outcome). Study quality was defined as poor when the score was $1-3$, fair when the score was $4-6$, and good when the score was 7-9 points.

\section{Data Items}

Data for study design, participant details, exclusion/inclusion criteria, interventions, and any comparators and outcomes were collected. The following variables were selected and included as outcome variables: Type of IDH definition that was used, the prevalence of IDH, systolic blood pressure (SBP) and/or diastolic blood pressure (DBP), and/or mean arterial pressure; prevalence of a decrease in SBP, DBP, or mean arterial pressure; prevalence and type of symptoms; prevalence and type of interventions.

\section{Statistical Analysis}

Characteristics of the HD patients were reported as mean $\pm \mathrm{SD}$, mean \pm SEM, and range or median with interquartile range.

For a proper comparison, studies were categorized into 5 types according to the definition or description of IDH: (1) a decrease in SBP of $\geq 20 \mathrm{~mm} \mathrm{Hg}$; (2) an intradialytic decrease in SBP of $\geq 20 \mathrm{~mm}$ $\mathrm{Hg}$ in combination with clinical events and interventions according to the European Best Practice Guideline (EBPG) on hemodynamic instability [13]; (3) an intradialytic nadir SBP below $90 \mathrm{~mm}$ $\mathrm{Hg}$ (Nadir <90); (4) studies with multiple cutoff values; and (5) studies in which there was no detailed information on the definition of IDH.

The frequency of IDH was reported as the percentage of HD sessions that fulfilled the study's criteria for IDH of the total number of HD sessions. These data were either directly available or could be calculated from the information in the manuscript.

The proportion of patients with frequent IDH was reported as the percentage of patients that met the criteria for frequent IDH as defined by the authors.

To assess the pooled estimate of the prevalence of IDH, metaanalyses were conducted when in 3 or more articles; the same definition of the prevalence of IDH was used. The weights of the meta-analyses were based on the inverse variance method; the heterogeneity parameter $\left(\mathrm{Tau}^{2}\right)$ for effect size was based on restricted maximum likelihood. The random effects model was selected for the mean difference because of expected differences in the number of patients and study duration between studies. Forest plots were constructed to summarize the outcome of the meta-analyses. An influence analysis was a component of each meta-analysis to check whether the conclusion critically depended upon the result of a single study. A test for funnel plot asymmetry based on the linear regression was added to indicate any risk of bias. The meta-analyses were performed using statistical programming language $\mathrm{R}(\mathrm{R}$ Core Team, 2018). $p$ values $<0.05$ were considered statistically significant. 
Fig. 1. Selection of articles for the systematic review on the prevalence of IDH. HD, hemodialysis; IDH, intradialytic hypotension

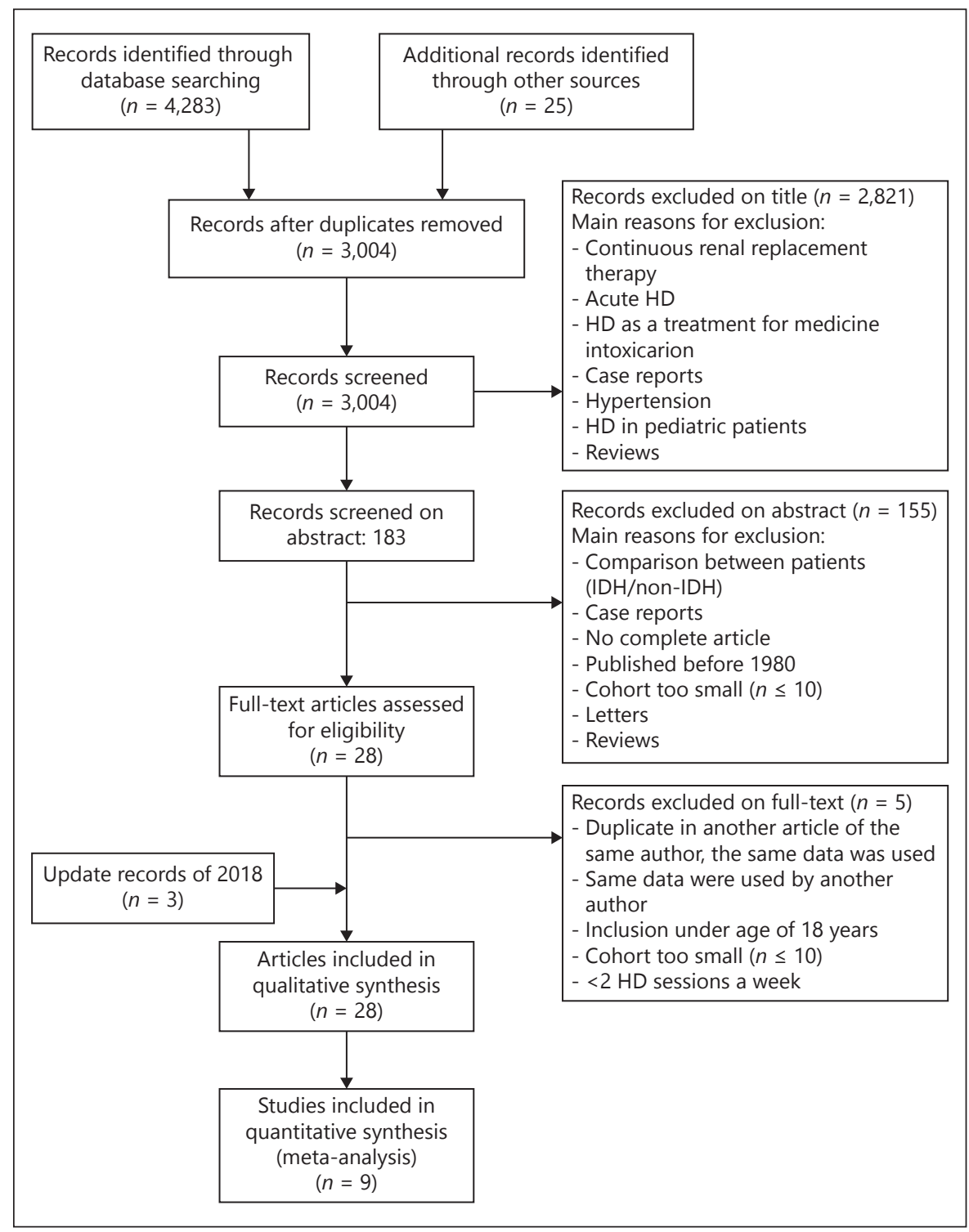

\section{Results}

\section{Search Results}

Figure 1 shows the flow diagram of the selection of articles. A total of 4,283 articles were identified, 2,124 in Pubmed, 2,159 in Embase, and 25 from other sources, such as searching citations and examinations of reference lists from relevant studies. After screening, a total of 1,279 duplicates were eliminated. Three thousand four articles were screened on title and abstract, resulting in 31 fulltext articles that were assessed for eligibility. From these, 5 articles were excluded for the following reasons: the number of HD sessions was equal to or $<2$ per week [14, 15], small number of patients [16], and the use of a data- base that was also used for another article included in this review [10, 17]. Finally, 26 articles were included for this systematic review.

\section{Characteristics of the Studies}

Table 1 summarizes patient characteristics and study quality of the 26 articles. The number of patients included varied between 28 and 112,013 patients. The mean age of patients ranged from 48.0 to 66.6 years, and most studies included adult patients ( $>18$ years) or age was not specified; Degoulet et al. [18] and Awan et al. [19] included patients with a minimum age of 10 and 15 years, respectively. The shortest dialysis vintage at the time that patients were included varied markedly between studies: 
Table 1. Summary of study characteristics

\begin{tabular}{|c|c|c|c|c|c|c|c|c|c|}
\hline Author & $\begin{array}{l}\text { Duration } \\
\text { studies, } \\
\text { days }\end{array}$ & $\begin{array}{l}\text { Number } \\
\text { of patients }\end{array}$ & $\begin{array}{l}\text { Men, } \\
n(\%)\end{array}$ & $\begin{array}{l}\text { Mean age, } \\
\text { years }\end{array}$ & $\begin{array}{l}\text { Diabetes } \\
(\%)\end{array}$ & $\begin{array}{l}\text { HD vintage, } \\
\text { months }\end{array}$ & $\begin{array}{l}\text { Number of } \\
\text { HD sessions } \\
\text { per week }\end{array}$ & $\begin{array}{l}\text { Duration } \\
\text { of session, } \mathrm{h}\end{array}$ & $\begin{array}{l}\text { Study } \\
\text { quality }\end{array}$ \\
\hline Agrawal et al. [30], 2012 & 183 & 28 & $19(68.0)$ & 48.8 (range $25-71$ ) & 17.9 & & 2 & 4 & 6 \\
\hline Akhmouch et al. [23], 2010 & 548 & 54 & $33(61.1)$ & 54.1 (range $21-80$ ) & 31.5 & 59.8 (range $5-240$ ) & 2.5 & 3.5 & 5 \\
\hline Al-Hilali et al. [37], 2004 & & 40 & $15(37.5)$ & $48.6 \pm 14.9$ & 45 & $34.5 \pm 2.7$ & & & 5 \\
\hline Awan et al. [19], 2011 & 91 & 100 & $57(57.0)$ & $51 \pm 16$ & 51 & & 2 & & 3 \\
\hline Bossola et al. [33], 2013 & 30 & 68 & $43(63.2)$ & $61 \pm 16$ & & $92 \pm 71$ & 3 & 4 & 6 \\
\hline Caplin et al. [6], 2011 & & 508 & $272(53.6)$ & 64 (IQR 60-74.5) & 36.3 & 37 (range $18-64$ ) & 3 & 4 & 5 \\
\hline Cho [24], 2017 & 7 & 191 & $49(25.7)$ & $60 \pm 12$ & 53.9 & & 3 & 4 & 6 \\
\hline Chou [21], 2018 & 91 & 112,013 & $63,847(57.0)$ & $63 \pm 15$ & 58 & & 3 & & 6 \\
\hline Collins et al. [38], 1993 & 183 & 40 & $16(40.0)$ & 52.5 (ns) & 425 & & 3 & 3.3 & 8 \\
\hline Davenport et al. [9], 2008 & 7 & 2,193 & $1,326(60.5)$ & $61.2(\mathrm{IQR} 46.9-72.3)$ & 32 & & 3 & 4 & 6 \\
\hline Degoulet et al. [18], 1981 & 365 & 1,110 & & $49 \pm 15.2$ & & & 3 & 4.6 & 5 \\
\hline Flythe et al. [5], 2014 (HEMO) & 183 & 1,409 & $625(44.4)$ & $59.4 \pm 13.4$ & 44.8 & & 3 & 3.5 & 8 \\
\hline Flythe et al. [5], 2014 (LDO) & 30 & 10,392 & $5,819(56.0)$ & $62.7 \pm 14.4$ & 60 & & 3 & 3.5 & 8 \\
\hline Kuipers et al. [25], 2016 & 91 & 124 & $69(50.6)$ & $64.1 \pm 15.7$ & 27 & $32 \pm 30.7$ & 3 & 4 & 5 \\
\hline Lai et al. [20], 2012 & 335 & 255 & $129(50.6)$ & 62.5 (range $16.0-93$ ) & 45.5 & & 3 & & 6 \\
\hline Levin [27], 2018 & 91 & 54 & $29(54.0)$ & $67.0 \pm 10.0$ & 56 & & & & 5 \\
\hline Meredith, 2015 & 30 & 77 & $55(71.0)$ & 65 (IQR 51-75) & 40.3 & 26 (IQR 11-49) & & & 5 \\
\hline Ogochukwu, 2017 & 1,460 & 404 & $225(55.7)$ & $48 \pm 17$ & & & & & 4 \\
\hline Orofino et al. [34], 1990 & 365 & 60 & $39(65.0)$ & 51 (range 15-72) & 0 & 41.7 (range 8-96) & 3 & 3.5 & 5 \\
\hline Rocha et al. [22], 2015 & 214 & 43 & $25(58.1)$ & $66.6 \pm 13.2$ & 27.9 & 86 (range 2-388) & 3 & 3.5 & 5 \\
\hline Sands et al. [36], 2014 & 579 & 1,137 & $608(53.5)$ & $61.9 \pm 15.8$ & 56.2 & $54 \pm 50.3$ & & 3.6 & 5 \\
\hline Sangala [26], 2017 & 83 & 432 & & $65.9 \mathrm{~ns}$ & 31 & $36.8 \mathrm{~ns}$ & 3 & & 6 \\
\hline Stefansson et al. [35], 2014 & 91 & 39,497 & $17,335(43.9)$ & $61.8 \pm 15.2$ & 68.2 & $3 \mathrm{~ns}$ & & & 6 \\
\hline Steinwandel [39], 2018 & 91 & 64 & $45(70.3)$ & $63.0 \pm 15.8$ & 28.1 & & 3 & 4 & 6 \\
\hline Straver et al. [31], 1998 & 1 & 68 & $38(55.9)$ & 56 (SEM 3.2) & 8.8 & 49 (SEM 8.8) & 2.5 & 3.5 & 5 \\
\hline Takeda et al. [29], 2006 & 91 & 111 & $63(64.9)$ & $60.5 \pm 11.6$ & 37.8 & $64 \pm 6.1$ & 3 & 4 & 5 \\
\hline Yu [28], 2018 & 91 & 293 & $180(61.4)$ & $55.7 \pm 14.1$ & 45 & $106.4 \pm 54.1$ & 3 & & 5 \\
\hline
\end{tabular}

IQR, inter quartile range; $\mathrm{HD}$, hemodialysis; ns, not specified.

1 month [20], 2 months [21, 22], 3 months [5, 6, 9, 19, 23-28], 6 months [29], and 12 months [23]. In 9 studies, the dialysis vintage was not specified (Table 1). Degoulet et al. [18] included only patients who were treated for $>50$ consecutive HD sessions during the follow-up period.

The majority of studies were based on a thrice weekly dialysis schedule with a duration of HD sessions between 3 and $5 \mathrm{~h}$. In 4 studies, the dialysis schedule nor the duration of the HD session was specified (Table 1). In 2 studies, the schedule was 2 HD sessions per week $[19,30]$, and 2 other studies used a dialysis schedule of twice or thrice weekly with a minimum duration of $3 \mathrm{~h}$ per HD session $[23,31]$. In 4 studies, the dialysis duration was not specified $[20,21,26,28]$. One study described a retrospective survey with 369 patients on 2 HD sessions per week and a group of 741 patients on $3 \mathrm{HD}$ sessions per week [18].

Exclusion criteria were not specified in 13 studies (online suppl. File 2). Two studies excluded patients because of incomplete or unavailable BP data [21,32], and 1 study specified that patients with acute renal failure were not included [30]. Three studies excluded patients with comorbidities [5, 28, 33] or diabetes [34] (online suppl. File 2).
Three types of study design were used among the included studies: cross-sectional study, prospective cohort study, and retrospective study. There were no randomized controlled trials among the studies. In the majority of studies, the research questions comprised the frequency of IDH and to identify patient or treatment factors associated with IDH or to assess the relationship between IDH and mortality (online suppl. File 2) [5, 21, 28, 35, 36]. A number of studies compared specific patient or treatment factors in order to establish which factor was associated with IDH, for example, interdialytic weight gain (IDWG) [20], antihypertensive medication [29], combined sodium and UF profiling [37], diabetes [9], dialysate temperature [34], and type of dialyzer used [38]. Detailed information on study design, primary research question, and use of $\mathrm{CV}$ medication is described in online supplementary File 2.

The score on the Newcastle Ottawa quality scale for cohort studies ranged from 3 to 8,1 study was evaluated as having poor quality (score 3) [19], 20 were assessed as having fair quality (score $4,5,6)$, and 2 studies as having good quality (score 8$)[5,38]$ (Table 1 ). 
Definitions of IDH

Of the included studies, 2 studies (including 1 study applying multiple definitions) had a decrease in SBP of $\geq 20 \mathrm{~mm} \mathrm{Hg}$ as main component in the definition. Ten other studies, including 2 studies applying multiple definitions $[5,39]$, used a decrease in SBP of $\geq 20 \mathrm{~mm} \mathrm{Hg}$ in combination with clinical events and interventions as definition of IDH. This definition is equivalent to the definition used in the EBPG guideline [13] and in the National Kidney Foundation Kidney Disease Outcomes Quality Initiative guideline [40]. In 6 studies, IDH was defined as Nadir $<90 \mathrm{~mm} \mathrm{Hg}$ including the study that used multiple definitions for 2 different cohorts [5]. Five studies used complicated definitions with multiple cutoff values, and another 5 studies lacked detailed information on the definition of IDH or described IDH nonspecifically as a sudden decrease in blood pressure (online suppl. File 2).

\section{Prevalence of IDH on Session Level}

Of the studies that measured the prevalence on session level, the percentage of HD sessions that was complicated by IDH ranged between 4.0 and $30.7 \%$ (online suppl. File 3). Of the studies that used the EBPG or a similar definition to identify IDH, there were 5 studies that measured the prevalence of IDH on session level. The prevalence of IDH in these studies ranged between $5.0 \%$ in a study with 54 patients and a total of 10,494 HD sessions during an observation period of 18 months [23] and $30.7 \%$ in a study with 43 patients with $18 \mathrm{HD}$ sessions per patient over a 1.5-month period [22] (online suppl. File 3).

Of the 6 studies that used the Nadir $<90$ definition, 5 studies reported the prevalence of IDH on session level. In these studies, the prevalence of IDH ranged between $4.0 \%$ in a study with 112,013 patients with a total number of 3,472,403 HD sessions during an observation period of 91 days [21] and $17.2 \%$ in a study with 1,137 patients with a total number of 44,801 HD sessions during an observation period of 579 days [36] (online suppl. File 3).

Three of the 5 studies that used IDH definitions with multiple cutoff values reported an IDH prevalence of $4.5 \%$ [30] and 5.4\% [19], and 23.3\% [27] at session level but did not specify the used definitions (online suppl. File 3).

Of the 5 studies that did not provide detailed information of the definition used, 2 studies reported an IDH prevalence of 4.8 [26] and 5.5\% [9] on session level (online suppl. File 3 ).

The Prevalence of IDH
Meta-Analysis of the Prevalence of IDH on Session

Level

The 5 studies that measured the prevalence of IDH on session level using the EBPG guideline or similar definitions were included in a meta-analysis comprising a total of 1,694 patients and 30,004 HD sessions. In a random effects model analysis, $10.1 \%$ (95\% CI 6.1-16.5) of IDH sessions were complicated by IDH (Fig. 2a). Homogeneity of effects was rejected in this analysis by a $p$ value of 0.01 (Fig. 2a). Influence analysis indicated no bias (online suppl. File 4a). The linear regression test of the funnel plot did not indicate significant evidence for asymmetry $(t=$ $0.54, p$ value $=0.6$ )

Of the 5 studies that reported the prevalence of IDH on session level using Nadir SBP $<90 \mathrm{~mm} \mathrm{Hg}$ as definition 4 were included in a meta-analysis comprising a total of 13,189 patients and 203,768 HD sessions. In a random effects model analysis, $11.6 \%$ (95\% CI 8.4-15.7) of HD sessions was complicated by IDH (Fig. 2b). Homogeneity of effects was rejected in this analysis by a $p$ value $<0.01$ (Fig. 2b). Influence analysis indicated no evidence for bias (online suppl. File $4 \mathrm{~b}$ ).

The study of Chou [21] was excluded from the primary meta-analysis because of the deviating inclusion criteria (they enrolled incident HD patients and evaluated the prevalence of IDH within the first 91 days of HD) in combination with a large number of patients. If the study of Chou [21] was included in meta-analysis, the random effect model analysis revealed that 9.7\% (95\% CI 5.2 to -17.5 ) of HD sessions was complicated by IDH.

\section{Proportion of Patients with Frequent IDH}

Seven studies provided information on the proportion of patients with frequent IDH defined according to the EBPG definition. In these studies, the proportion of patients with frequent IDH ranged from 5.6 to $76.7 \%$ (Fig. 3a).

Six studies give information on the proportion of patients with frequent IDH defined as the Nadir $<90$ definition. In these 6 studies, the proportion of patients with frequent IDH ranged from 10.1 to $75.1 \%$ (Fig. 3b).

Of the 5 studies that used definitions with multiple cutoff values, 2 reported a proportion of patients with frequent IDH was 57\% [38] and 26\% [27]. In the 5 studies that did not provide detailed information on the IDH definition, the proportion of patients with frequent IDH ranged between $4.8 \%$ [26] and 76.4\% [6], (online suppl. File 3). A meta-analysis of proportions on patient level was not possible given the large difference in cutoff values between studies. 


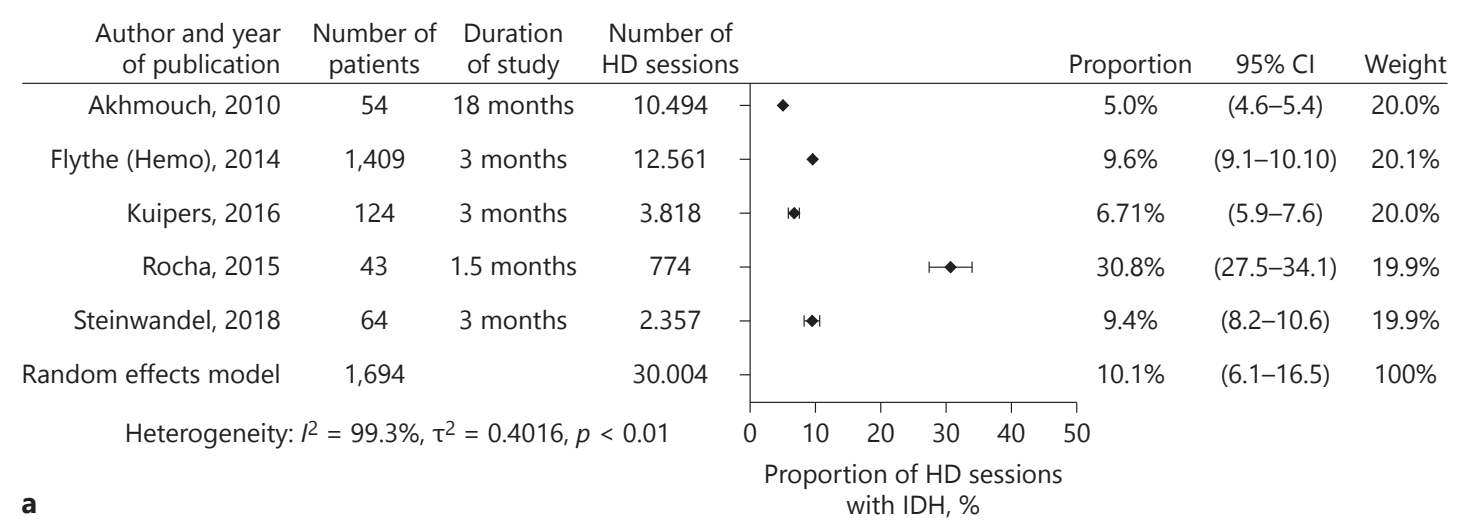

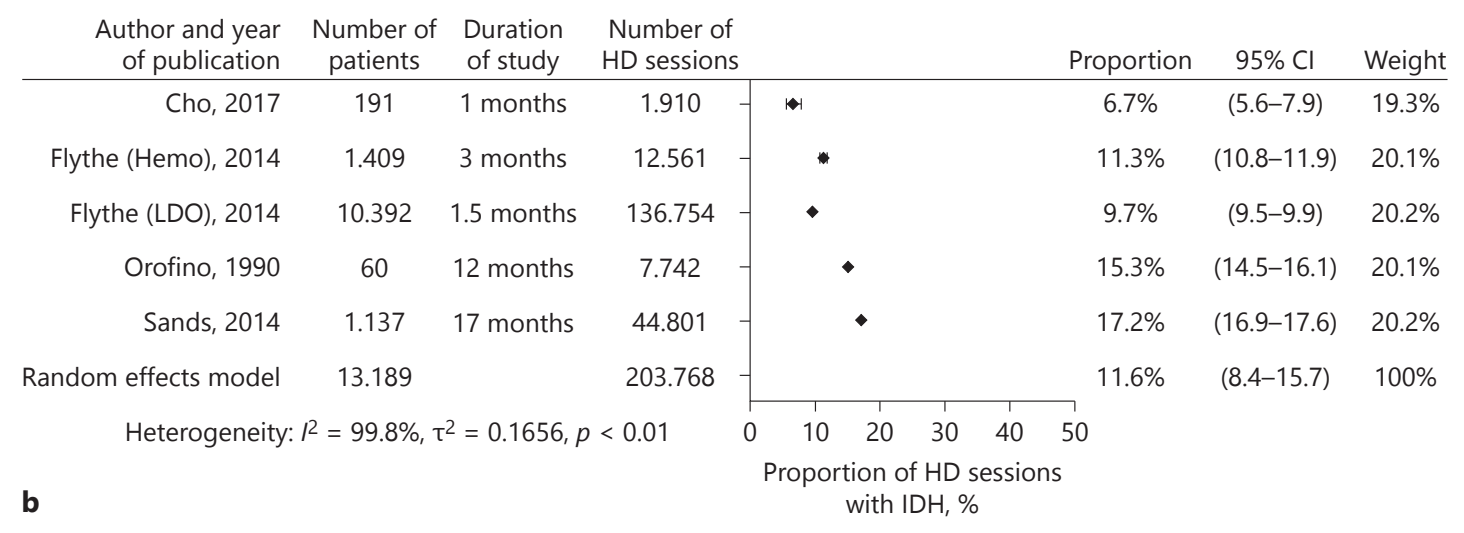

Fig. 2. a Prevalence of IDH defined according to the EBPG definition on session level with a meta-analysis. b Prevalence of IDH defined according to the SBP nadir $<90 \mathrm{~mm} \mathrm{Hg}$ definition on session level with meta-analysis. HD, hemodialysis; IDH, intradialytic hypotension.

\section{Symptoms of IDH}

Symptoms of IDH and/or the need for nursing interventions were described in 8 studies using various definitions and methodology (online suppl. File 5).

The most common symptoms were cramps, nausea, vomiting, and dizziness. Caplin et al. [6] reported that cramps occurred in $74.3 \%$ of $\mathrm{HD}$ sessions, whereas Agrawal et al. [30] described cramps in $0.8 \%$ of HD sessions (online suppl. File 5).

\section{Interventions}

Interventions were described in 3 studies. Kuipers et al. [25] reported interventions in $8.5 \%$ of HD sessions; Ogochukwu observed interventions in $28.5 \%$ of HD sessions; Collins et al. [38] reported interventions occurring in $29.2 \%$ of HD sessions, defined as saline administration during episodes of symptomatic hypotension or cramping (online suppl. File 5).

\section{Hemodynamic Data}

Hemodynamic data were available in 20 studies (online suppl. File 6). Pre-HD SBP was mostly described and ranged from 128 to $156 \mathrm{~mm} \mathrm{Hg}$. Post-HD SBP ranged from 106 to $144 \mathrm{~mm} \mathrm{Hg}$. Pre-HD DBP ranged from 67 to $84 \mathrm{~mm} \mathrm{Hg}$. Post HD DPB ranged from 59 to $74 \mathrm{~mm} \mathrm{Hg}$. IDWG varied from 2.2 to $4.5 \mathrm{~L}$. Total UF per HD session ranged from 1.7 to $2.9 \mathrm{~L}$ (online suppl. File 6).

\section{Patient and Treatment Factors Associated with IDH}

Fourteen studies described specific patient or treatment factors that were related to IDH. The most commonly reported patient-related factors were the presence of diabetes $[9,18,22,23,28,29,35,36]$ and a higher IDWG $[19,20,25,29,33,35,36]$. Both factors together were mentioned in 3 studies [29, 35, 36].

Being female was mentioned as a risk factor for IDH in 7 studies [18, 19, 25, 28, 34, 36, 39]. In 1 study, female 


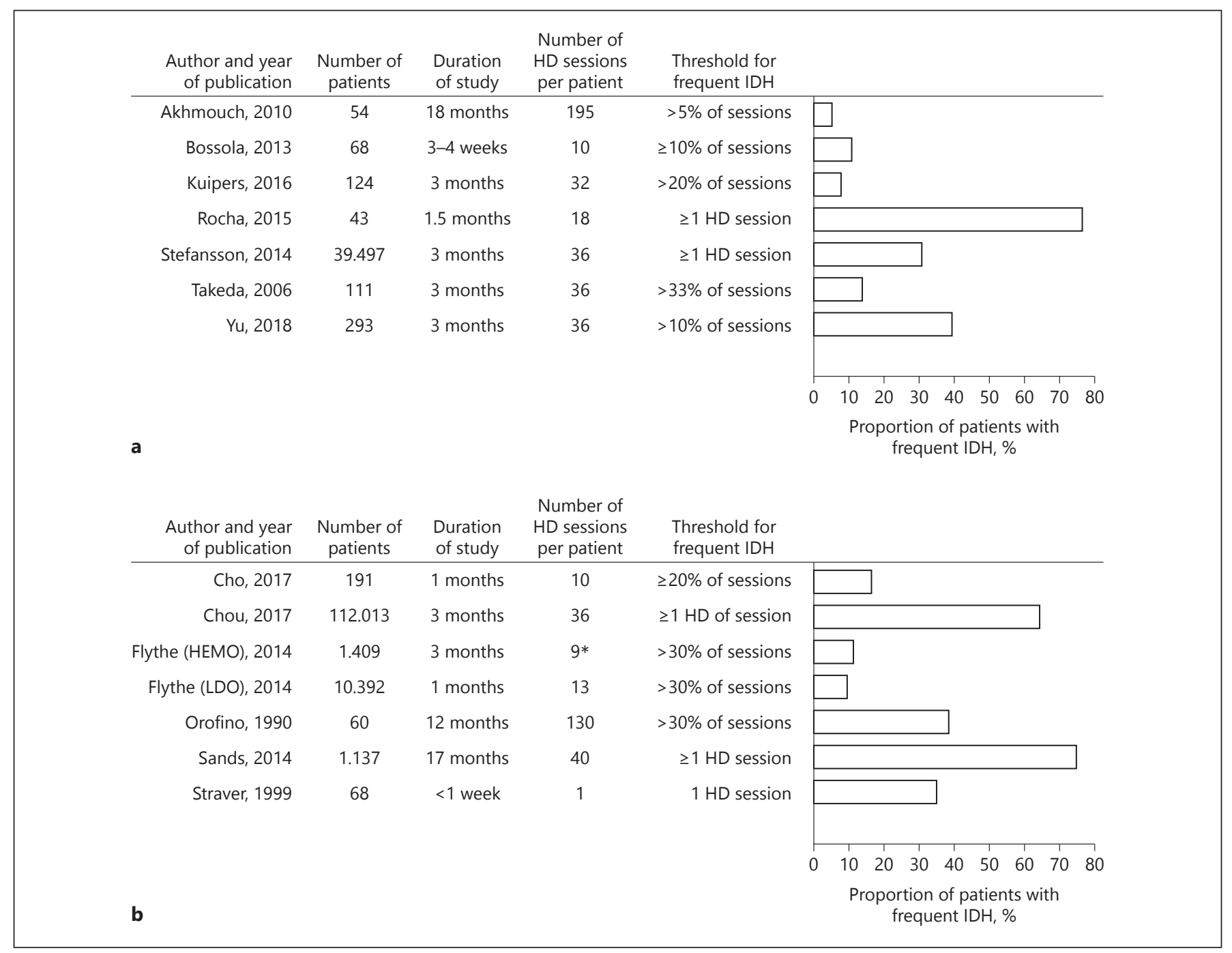

Fig. 3. a Proportion of patients with frequent IDH as defined according to the EBPG definition. b Proportion of patients with frequent IDH as defined according to the SBP nadir $<90 \mathrm{~mm} \mathrm{Hg}$ definition. HD, hemodialysis; IDH, intradialytic hypotension.

gender was identified as a risk factor in combination with the factors IDWG and UF rate [19]. In 2 other studies, female gender was found to be a risk factor in combination with lower body weight $[25,34]$, one of these studies also found small height as a risk factor [25].

Low predialysis SBP was reported as a risk factor for IDH in 3 studies [26, 28, 34, 36], whereas another study identified a high SBP as a risk factor for IDH [25].

In 2 studies, dialysate temperature was identified as a risk factor for IDH. A higher temperature ( 37 vs. $35^{\circ} \mathrm{C}$ ) was associated with a higher rate of symptomatic IDH in one of these studies [41].

\section{Discussion/Conclusion}

The major conclusion of this review is that, as seen in our meta-analysis, the prevalence of IDH according to both the EBPG (10.1\%) and the Nadir $<90 \mathrm{~mm} \mathrm{Hg}$ definition (11.6\%) was much lower than the 20 to $30 \%$ prevalence that is stated in most reviews [36, 41-47]. The proportion of patients with frequent IDH varied between studies, in part depending on the threshold that is used to identify patients with frequent IDH. Major risk factors associated with IDH across studies were diabetes, a higher IDWG, female gender, and lower body weight. 
Interestingly, the studies within the EBPG definition showed a rather uniform pattern with a prevalence of IDH below $12 \%$ with only one exception: Rocha et al. [22] reported that as much as $30.7 \%$ of HD sessions were complicated by IDH. These authors included multiple episodes of IDH during a single HD session, whereas in most studies, HD sessions with IDH were considered as one event. For the Nadir $<90 \mathrm{~mm} \mathrm{Hg}$ definition, there was more variation between studies with the prevalence ranging between 4.0 and $17.2 \%$ of HD sessions.

If a liberal definition of IDH is used such as a fall in $\mathrm{SBP}>20 \mathrm{~mm} \mathrm{Hg}$, the prevalence will be higher than when stricter definitions are used, such as the EBPG definition. However, even within a homogenous category of, for instance, the EBPG definition, it remains difficult to compare studies for several reasons. First, studies differed markedly with regard to the number of patients included, the observation period, and whether IDH was measured on session level or on patient level. Second, the prevalence of symptoms may differ depending on how these data were collected with "actively" using questionnaires at each dialysis session, yielding a higher prevalence than "passively" waiting for the patient to report symptoms. Finally, an intervention is, like a symptom, not a hard end point but is subject to bias with variation in the threshold to start an intervention between health-care professionals. Notably, most of the studies lacked a detailed description of the interventions that were used to treat IDH; only 1 study [25] described specific interventions other than the administration of fluid.

Despite the differences between the studies, there was a similarity in the factors that were associated with IDH across studies. Diabetes is an obvious risk factor for IDH, explained by a higher prevalence of cardiovascular complications and diabetic complications such as autonomous neuropathy [9]. Higher IDWG is also a well-known risk factor for the occurrence of IDH [48-50]. Rocha et al. [22] found a significant association between lower dry weight and recurrent IDH episodes. A higher refill rate from the interstitial tissues in a more fluid overloaded state can be seen as the cause of the higher BP during the first HD session of the week [51].

Female gender was reported as a risk factor for IDH in 7 studies [18, 19, 25, 28, 34, 36, 39]. Notably, 2 studies reported female gender in combination with a lower body weight as a risk factor for IDH $[25,34]$. This can be explained by the fact that females in general have a lower body weight than men and, consequently, have a higher UF rate $(\mathrm{mL} / \mathrm{h} / \mathrm{kg}$ bodyweight) during $\mathrm{HD}$ for a similar IDWG.
Although we did a broad search of the available literature and included the studies that actually investigated the prevalence of IDH, we cannot exclude the possibility of publication bias. However, the funnel plot did not indicate significant evidence for publication bias. The literature search showed that the EBPG and the nadir $<90$ $\mathrm{mm} \mathrm{Hg}$ definition are most frequently used. In our opinion, it is justified to perform a meta-analysis for studies using these definitions despite the differences in the number of patients investigated and the number HD treatments between studies. A limitation of this analysis is the significant heterogeneity across studies. However, the random effects model and the influence analysis by leaving one study out showed that the results of the prevalence of IDH were robust. Although these results show a lower than expected pooled estimates, the content evaluation makes the results appear reasonable given the current state of literature in the field of IDH in HD patient.

Presently, there is no general consensus regarding the best evidence-based indicators of IDH. Surprisingly, in none of the articles it was stated what the underlying motivation was for the use of that specific definition. Depending on the purpose of the study, the appropriate definition may differ as also stated by Assimon and Flythe [52]. In our opinion, the definition of IDH should be refined based on the purpose for which the definition is used. Thus, when the goal of the study is to examine the relation between IDH and outcome, a nadir definition may be appropriate whereas when the purpose of the study is to investigate the relation between IDH and patient reported outcome measurements or quality of life a definition of IDH that incorporates intradialytic (and preferably also post-dialytic) symptoms may be more relevant. Further research is needed to understand the underlying mechanisms of IDH and its symptoms in order to provide the patient with the optimal dialysis treatment. This is relevant not only for preventing morbidity and decreasing mortality but also to support patients in their well-being and to improve quality of life.

\section{Acknowledgments}

Monique Kuiken and Maaike Agema are acknowledged for their contribution to this article in the context of their internship for the Hanzehogeschool.

\section{Statement of Ethics}

The authors have no ethical conflicts to disclose. 


\section{Disclosure Statement}

The authors have no conflicts of interest to declare.

\section{Funding Sources}

The study was funded by the Dialysis Center Groningen.

\section{Author Contributions}

J.K. and L.M.V.: collected and reviewed the articles. W.P.K., W.P., C.F.M.F., and J.K.: contributed substantially to the analysis and interpretation of data and have been involved in drafting the manuscript. R.W., C.A.J.M.G., J.I., and L.M.V.: have been involved in drafting and revising the manuscript and have given final approval of the version to be published.

\section{References}

1 Tislér A, Akócsi K, Borbás B, Fazakas L, Ferenczi S, Görögh S, et al. The effect of frequent or occasional dialysis-associated hypotension on survival of patients on maintenance haemodialysis. Nephrol Dial Transplant. 2003 Dec;18(12):2601-5.

2 Shoji T, Tsubakihara Y, Fujii M, Imai E. Hemodialysis-associated hypotension as an independent risk factor for two-year mortality in hemodialysis patients. Kidney Int. 2004 Sep;66(3):1212-20.

3 Chang TI, Paik J, Greene T, Desai M, Bech F, Cheung AK, et al. Intradialytic hypotension and vascular access thrombosis. J Am Soc Nephrol. 2011 Aug;22(8):1526-33.

4 McIntyre CW. Haemodialysis-induced myocardial stunning in chronic kidney disease - a new aspect of cardiovascular disease. Blood Purif. 2010;29(2):105-10.

5 Flythe JE, Xue H, Lynch KE, et al. Association of mortality risk with various definitions of intradialytic hypotension. J Am Soc Nephrol. 2015 Mar;26(3):724-34.

6 Caplin B, Kumar S, Davenport A. Patients' perspective of haemodialysis-associated symptoms. Nephrol Dial Transplant. 2011 Aug;26(8):2656-63.

7 Jefferies HJ, Burton JO, McIntyre CW. Individualised dialysate temperature improves intradialytic haemodynamics and abrogates haemodialysis-induced myocardial stunning, without compromising tolerability. Blood Purif. 2011;32(1):63-8.

8 Franssen CF, Dasselaar JJ, Sytsma P, Burgerhof JG, de Jong PE, Huisman RM. Automatic feedback control of relative blood volume changes during hemodialysis improves blood pressure stability during and after dialysis. Hemodial Int. 2005 Oct;9(4):383-92.

9 Davenport A, Cox C, Thuraisingham R Blood pressure control and symptomatic intradialytic hypotension in diabetic haemodialysis patients: a cross-sectional survey. Nephron Clin Pract. 2008;109(2):c65-71.

10 Mc Causland FR, Brunelli SM, Waikar SS. Dialysis dose and intradialytic hypotension: results from the HEMO study. Am J Nephrol. 2013;38(5):388-96.

11 Liberati A, Altman DG, Tetzlaff J, Mulrow C, Gøtzsche PC, Ioannidis JP, et al. The PRISMA statement for reporting systematic reviews and meta-analyses of studies that evaluate health care interventions: explanation and elaboration. PLoS Med. 2009 Jul;6(7): e1000100

12 Wells GA, Shea B, O'Connell D, Peterson J, Welch V, Losos M, et al. The newcastle-ottawa scale (NOS) for assessing the quality of nonrandomised studies in meta-analysis. Clinical Epidemiology. Available from: http:// www.ohri.ca/programs/clinical_epidemiology.oxford.htm. 2004.

13 Kooman J, Basci A, Pizzarelli F, Canaud B, Haage $\mathrm{P}$, Fouque $\mathrm{D}$, et al. EBPG guideline on haemodynamic instability. Nephrol Dial Transplant. 2007 May;22 Suppl 2:ii22-44.

14 Shaikh RA, Solangi S, Rathi SK, et al. Frequency of acute complications during haemodialysis. J Liaquat Univ Med Health Sci. 2013;12(2):94-7.

15 Amira CO, Braimoh RW, Bello BT. Pattern of intradialytic complications at the lagos university teaching hospital. Afr J Med Med Sci. 2012 Dec;41(4):411-6.

16 Ghaffar U. A quality improvement project: Strategies to reduce intradialytic hypotension in hemodialysis patients. Nephrol News Issues. 2015 May;29(5):30, 32, 34 passim.

17 Rocha A, Sousa C, Teles P, Coelho A, Xavier E. Effect of dialysis day on intradialytic hypotension risk. Kidney Blood Press Res. 2016; 41(2):168-74

18 Degoulet P, Réach I, Di Giulio S, Devriès C, Rouby JJ, Aimé F, et al. Epidemiology of dialysis induced hypotension. Proc Eur Dial Transplant Assoc. 1981;18:133-8.

19 Awan AU, Shafi T, Ahmed AM, et al. Frequency of intradialytic hypotension among patients on maintenance heamodialysis. Pak J Med Health Sci. 2011;5(3):471-5.

20 Lai CT, Wu CJ, Chen HH, Pan CF, Chiang CL, Chang CY, et al. Absolute interdialytic weight gain is more important than percent weight gain for intradialytic hypotension in heavy patients. Nephrology (Carlton). 2012 Mar;17(3):230-6.

21 Chou JA, Streja E, Nguyen DV, Rhee CM, Obi $\mathrm{Y}$, Inrig JK, et al. Intradialytic hypotension, blood pressure changes and mortality risk in incident hemodialysis patients. Nephrol Dial Transplant. 2018 Jan 1;33(1):149-59.

22 Rocha A, Sousa C, Teles P, Coelho A, Xavier E. Frequency of intradialytic hypotensive episodes: old problem, new insights. I Am Soc Hypertens. 2015 Oct;9(10):763-8.
23 Akhmouch I, Bahadi A, Zajjari Y, Bouzerda A, Asserraji M, Alayoud A, et al. Characteristics of intradialytic hypotension: experience of Agadir Center-Morocco. Saudi J Kidney Dis Transpl. 2010 Jul;21(4):756-61.

24 Cho A, Lee YK, Oh J, Yoon JW, Shin DH, Jeon $\mathrm{HJ}$, et al. The relationship between intradialytic hypotension and vascular calcification in hemodialysis patients. PLoS One. 2017 Oct; 12(10):e0185846.

25 Kuipers J, Oosterhuis JK, Krijnen WP, Dasselaar JJ, Gaillard CA, Westerhuis R, et al. Prevalence of intradialytic hypotension, clinical symptoms and nursing interventions-a three-months, prospective study of 3818 haemodialysis sessions. BMC Nephrol. $2016 \mathrm{Feb}$ 17(1):21.

26 Sangala N, Gangaram V, Atkins K, Elliot G, Lewis R. Intra-dialytic hypotension: identifying patients most at risk. J Ren Care. 2017 Jun; 43(2):92-7.

27 Levin NW, de Abreu MH, Borges LE, Tavares Filho HA, Sarwar R, Gupta S, et al. Hemodynamic response to fluid removal during hemodialysis: categorization of causes of intradialytic hypotension. Nephrol Dial Transplant. 2018 Sep;33(9):1643-9.

28 Yu J, Liu Z, Shen B, Teng J, Zou J, Ding X. Intradialytic hypotension as an independent risk factor for long-term mortality in maintaining hemodialysis patients: A 5-year follow-up cohort study. Blood Purif. 2018;45(4): 320-6.

29 Takeda A, Toda T, Fujii T, Sasaki S, Matsui N. Can predialysis hypertension prevent intradialytic hypotension in hemodialysis patients? Nephron Clin Pract.2006;103(4):c13743.

30 Agrawal RK, Khakurel S, Hada R, Shrestha D, Baral A. Acute intradialytic complications in end stage renal disease on maintenance hemodialysis. JNMA J Nepal Med Assoc. 2012 Jul-Sep;52(187):118-21.

31 Straver B, Roggekamp MC, de Vries PM, ter Wee PM. Systemic vascular resistance in intradialytic hypotension determined by means of impedance cardiography. Blood Purif. 1998;16(5):281-9.

32 Okoye OC, Slater HE, Rajora N. Prevalence and risk factors of intra-dialytic hypotension: a 5 year retrospective report from a single $\mathrm{Ni}$ gerian Centre. Pan Afr Med J. 2017 Sep;28:62. 
33 Bossola M, Laudisio A, Antocicco M, Panocchia N, Tazza L, Colloca G, et al. Intradialytic hypotension is associated with dialytic age in patients on chronic hemodialysis. Ren Fail. 2013 Oct;35(9):1260-3.

34 Orofino L, Marcén R, Quereda C, Villafruela JJ, Sabater J, Matesanz R, et al. Epidemiology of symptomatic hypotension in hemodialysis: is cool dialysate beneficial for all patients? Am J Nephrol. 1990;10(3):177-80.

35 Stefánsson BV, Brunelli SM, Cabrera C, Rosenbaum D, Anum E, Ramakrishnan K, et al. Intradialytic hypotension and risk of cardiovascular disease. Clin J Am Soc Nephrol. 2014 Dec;9(12):2124-32.

36 Sands JJ, Usvyat LA, Sullivan T, Segal JH, Zabetakis $\mathrm{P}$, Kotanko $\mathrm{P}$, et al. Intradialytic hypotension: frequency, sources of variation and correlation with clinical outcome. Hemodial Int. 2014 Apr;18(2):415-22.

37 Al-Hilali N, Al-Humoud HM, Ninan VT, Nampoory MR, Ali JH, Johny KV. Profiled hemodialysis reduces intradialytic symptoms. Transplant Proc. 2004 Jul-Aug;36(6):1827-8.

38 Collins DM, Lambert MB, Tannenbaum JS, Oliverio M, Schwab SJ. Tolerance of hemodialysis: a randomized prospective trial of high-flux versus conventional high-efficiency hemodialysis. J Am Soc Nephrol. 1993 Aug;4(2):148-54.
39 Steinwandel U, Gibson N, Towell-Barnard M, Parsons R, Rippey JJ, Rosman J. Measuring the prevalence of intradialytic hypotension in a satellite dialysis clinic: are we too complacent? J Clin Nurs. 2018 Apr;27(7-8):e156170.

$40 \mathrm{~K} / \mathrm{DOQI}$ Workgroup. K/DOQI clinical practice guidelines for cardiovascular disease in dialysis patients. Am J Kidney Dis. 2005 Apr; 45(4 Suppl 3):S1-153.

41 Daugirdas JT. Pathophysiology of dialysis hypotension: an update. Am J Kidney Dis. 2001 Oct;38(4 Suppl 4):S11-7.

42 Davenport A. Can advances in hemodialysis machine technology prevent intradialytic hypotension? Semin Dial. 2009 May-Jun;22(3): 231-6.

43 Perazella MA. Pharmacologic options available to treat symptomatic intradialytic hypotension. Am J Kidney Dis. 2001 Oct;38(4 Suppl 4):S26-36.

44 Dubin R, Owens C, Gasper W, Ganz P, Johansen $\mathrm{K}$. Associations of endothelial dysfunction and arterial stiffness with intradialytic hypotension and hypertension. Hemodial Int. 2011 Jul;15(3):350-8.
45 Passauer J, Büssemaker E, Gross P. Dialysis hypotension: do we see light at the end of the tunnel? Nephrol Dial Transplant. 1998 Dec; 13(12):3024-9.

46 Daugirdas JT. Preventing and managing hypotension. Semin Dial. 1994;7(4):276-83

47 Zucchelli P, Santoro A. Dialysis-induced hypotension: a fresh look at pathophysiology. Blood Purif. 1993;11(2):85-98.

48 Hall JE, Guyton AC, Brands MW. Pressurevolume regulation in hypertension. Kidney Int Suppl. 1996 Jun;55:S35-41.

49 Koomans HA, Braam B, Geers AB, Roos JC, Dorhout Mees EJ. The importance of plasma protein for blood volume and blood pressure homeostasis. Kidney Int. 1986 Nov;30(5): 730-5.

50 Ventura JE, Spósito M. Volume sensitivity of blood pressure in end-stage renal disease. Nephrol Dial Transplant. 1997 Mar;12(3): $485-91$.

51 Koomans HA, Geers AB, Mees EJ. Plasma volume recovery after ultrafiltration in patients with chronic renal failure. Kidney Int. 1984 Dec;26(6):848-54.

52 Assimon MM, Flythe JE. Intradialytic blood pressure abnormalities: the highs, the lows and all that lies between. Am J Nephrol. 2015; 42(5):337-50. 